\title{
CORRELATION BETWEEN MASTICATORY PERFORMANCE AND QUALITY OF LIFE OF PATIENTS USING POSTERIOR DENTAL IMPLANTS
}

\author{
YAYUK SUPATMI RAHAYU ${ }^{1}$, RATNA SARI DEWI ${ }^{2 *}$, ROSELANI ODANG ${ }^{2}$, CHAIDAR MASULILI $^{2}$ \\ ${ }^{1}$ Department of Prosthodontic Residency Program, Faculty of Dentistry, Universitas Indonesia, Jakarta, Indonesia. ${ }^{2}$ Department of \\ Prosthodontic, Faculty of Dentistry, Universitas Indonesia, Jakarta, Indonesia. Email: Ratnasaridewi.drg@gmail.com
}

Received: 16 September 2017, Revised and Accepted: 3 October 2017

\section{ABSTRACT}

Introduction: Masticatory performance measurement to evaluate a patient's satisfaction with dentures, including patients using posterior implantsupported single crowns, contributes to prosthetic treatment. Patient satisfaction rates can affect their quality of life (QoL). However, in Indonesia, these evaluations are rarely made.

Objective: This study objective was to investigate the correlation of masticatory performance to oral health-related QoL in patients using posterior implant-supported single crowns.

Methods: The study design was cross-sectional using twelve patients with posterior implant-supported single crowns. The study used sociodemographic data, a QoL questionnaire, and color-changeable chewing gum (Xylitol). A Spearman correlation was used to analyze the data. No significant correlation ( $p>0.05$ ) was found between masticatory performance and oral health impact profile (OHIP) score.

Results: This result study was expected because of the small number of subjects in the study. It is suggested that masticatory performance can be assessed objectively with color-changeable chewing gum and subjectively with a QoL questionnaire (OHIP 49-id).

Keywords: Masticatory performance, Quality of life, Posterior implant-supported single crown.

(C) 2017 The Authors. Published by Innovare Academic Sciences Pvt Ltd. This is an open access article under the CC BY license (http://creativecommons. org/licenses/by/4. 0/) DOI: http://dx.doi.org/10.22159/ijap.2017.v9s2.37

\section{INTRODUCTION}

In recent years, Osseointegrated implants have increasingly been used in prosthodontics. Implant-supported single crowns are frequently used to replace missing single teeth, and studies have focused on implant survival rates and biological and technical complications [1]. Replacement of a single missing tooth with dental implants has high success rates and does not compromise the adjacent natural dentition [2]. The advantages of a posterior implant single tooth replacement are as follows[3]:

1. High success rates (above $97 \%$ for 10 years).

2. Decreased risk of caries of adjacent teeth.

3. Decreased risk of endodontics problems on adjacent teeth.

4. Improved ability to clean the proximal surfaces of the adjacent teeth.

5. Improved esthetics of adjacent teeth.

6. Improved maintenance of bone in edentulous site.

7. Decreased cold or contact sensitivity of adjacent teeth.

8. Psychological advantage.

9. Decreased abutment tooth loss.

From 1993 to the present day, single tooth implants have been shown to be the most predictable method of tooth replacement. Posterior implants reduce the risks that fixed partial dentures present. These risks include challenging support from available teeth, retention and resistance from abutments, and the limitations of materials available to fabricate these prostheses. Posterior implant single tooth replacements are useful to avoid incorporation of compromised abutment teeth into a prosthesis and where abutment teeth are not available, and therefore, a long-span fixed partial denture can no longer fabricated.

Dental implants allow for segmentation of a restoration and provide support to a restoration without depending on abutment teeth. The broad use of implants in posterior quadrants is not exclusively based on favorable long-term outcomes. Other factors such as biomechanical advantages and availability of prefabricated components have made this treatment modality appealing to clinicians. Implant-retained restorations present considerable advantages over removable partial dentures for missing posterior teeth including improved support, a more stable occlusion, preservation of bone, and simplification of the prosthesis.

Oral health changes, such tooth loss can have a profound effect on a patient's quality of life (QoL) [4]. Tooth loss implies in loss of several orofacial structures, such as bone tissues, nerves, receptors, and muscles, and consequently, most orofacial functions are diminished. Studies have indicated that the decrease of a number of teeth and for complete denture wearers the chew's ability is significantly less efficient and this may have consequences over general health and QoL of those patients.

The negative impact on oral health-related QoL may also be due to poor speech, pain, and dissatisfaction with appearance [5]. Individuals with $<25$ teeth have higher scores in self-administered oral health impact profile (OHIP) questionnaires than those with more teeth. In general, prosthetic patients attribute mastication and the appearance of their prosthesis as having the highest significance [6].

Dental implant is a popular method replacing one or more missing teeth [7]. Dental implants support either a fixed or removable prosthesis and can provide a significant benefit to partially or fully edentulous patients [4]. Edentulous patients treated with dental implants to support prostheses have better masticatory function, higher satisfaction, and QoL than patients treated with conventional complete mandibular dentures [8].

Although replacement and restoration of implanted supported single crowns are considered a routine procedure, reports of their effect on oral function and daily life are limited, including in Indonesia. 
Self-reported masticatory ability is dependent on the number of teeth [6]. In addition, the masticatory performance and efficiency, maximum molar bite force, and the maximum activity in jaw elevator muscles are positively correlated with occlusal contacts, occlusal area of natural teeth, and the number of posterior teeth [9]. During chewing, the basic masticatory rhythm is controlled by a central pattern generator supplemented by centers in the motor cortex and the basal ganglia and modified by peripheral information and reflexes from the masticatory system [9]. Especially, afferent activity from the periodontal mechanoreceptors is important for peripheral control of the masticatory muscles and the continuous modulation of the masticatory motor pattern [9]. Research suggests that osseoperception of implants is secondary to nerve in growth into remodeling bone, as controlled by neuropeptides such as calcitonin gene-related peptide.

The evidence available on the plasticity of the central nervous system (CNS) provides a possible neural basis for our understanding of accommodation of patients to the changes in dental status. The CNS has specialized mechanism for obtaining information about the positions and movements of limbs and forces of limb muscle contraction (limb kinesthesia). The mechanism is solely derived from mechanoreceptors activated during limb movements and likely for oral kinesthetic perception also. To control oral motor behaviors such as biting, speech, and oral manipulation, the brain relies on information from sense organs in the orofacial structures. Natural teeth are equipped with extremely sensitive tactile sensors-periodontal mechanoreceptors. These sensors provide information about tooth loads and are located in periodontal ligaments. In the content of implant-supported prostheses, the term osseoperception was proposed to recognize oral kinesthetic perceptual abilities, in the absence of a functional periodontal mechanoreceptive input. This input is derived from temporomandibular joint, muscle, cutaneous, mucosal, and/or periosteal mechanoreceptors and provide mechanosensory information for oral kinesthetic sensibility in relation to jaw function and artificial tooth contacts [7].

Mastication is a complex process characterized by the communication and breakdown of food into smaller particles to increase surface area, stimulate enzymatic function, and improve the digestibility of food. Masticatory efficiency can be measured by counting the number of chewing strokes required to reduce food to a certain particle size before swallowing, and masticatory performance is measured by assessing the particle size distribution of food when chewed for a given number of stroke [10]. Many clinical assessment methods were developed to assess masticatory performance, for example, color-changing chewing gum, sieving comminuted food or artificial food, optical scanning of masticated particles, or measuring the release of dye when chewing food. Currently, there are many different methods used to clinically assess masticatory performance objectively [11].

A new color-changeable chewing gum (Masticatory Performance Evaluating Gum XYLITOL) has been developed as a test item. Methods using this chewing gum, for which color change as chewing proceeds, can be used to evaluate masticatory performance by measuring changes in gum color. Color changes are measured using a hand-held colorimeter and a color scale. This method is easy, simple, and quick, with no need for bulky equipment, and it has advantages in stimulating a natural and stable act of chewing while still allowing complete recovery of the test item. Color-changeable chewing gum has been applied in various fields [12]

The aim of the current study was to investigate the correlation between masticatory performance objectively assessed with color-changeable chewing gum and QoL subjectively assessed with OHIP 49-id (now being validated in Indonesia) in patients with posterior implant singlesupported crowns.

\section{METHODS}

\section{Study design and patients}

Assessment of masticatory function was made both subjectively and objectively. Patients completed self-administered questionnaires,
Table 1: Distribution on patients based on sociodemographic and number of implant

\begin{tabular}{ll}
\hline Variable & Frequency (\%) \\
\hline Age (year) & \\
$\quad<50$ & $6(50)$ \\
$\geq 50$ & $6(50)$ \\
Sex & $6(50)$ \\
Female & $6(50)$ \\
Male & \\
Level of education & $5(41)$ \\
$\quad$ High school & $7(59)$ \\
College & \\
Job & $5(41)$ \\
Civil & $7(59)$ \\
Private center & $7(59)$ \\
Number of implants & $5(41)$ \\
$\quad$ Single & \\
Multiple & \\
\hline
\end{tabular}

Table 2: Masticatory performance and total OHIP score

\begin{tabular}{lll}
\hline & $\begin{array}{l}\text { Mastication } \\
\text { performance }\end{array}$ & Total OHIP score \\
\hline Mean & 7.25 & - \\
SD & 0.86 & - \\
Median & - & 15 \\
Minimum-maximum & - & $(2-66)$ \\
\hline
\end{tabular}

OHIP: Oral health impact profile, SD: Standard deviation

Table 3: Correlation between masticatory performance and other variables with total OHIP score

\begin{tabular}{lll}
\hline Variable & $\mathbf{p}$ & $\mathbf{r}$ \\
\hline Mastication performance & 0.595 & 0.171 \\
Age & 0.534 & -0.200 \\
Sex & 0.882 & -0.048 \\
Level of education & 0.044 & 0.589 \\
Job & 0.313 & -0.318 \\
Number of implants & 0.961 & -0.016 \\
\hline
\end{tabular}

OHIP: Oral health impact profile

and masticatory performance was clinically evaluated with colorchangeable chewing gum.

The study included 12 participants: Six women and six men in the age range of 27-64 years with posterior implant-supported single crowns who had been treated at the Faculty of Dentistry, Universitas Indonesia dental clinic, and recalled to participate in this study. Eligibility criteria included patients who had posterior implant-supported single crowns for least 4 months, who were willing to participate, who had good general health, who opposing natural teeth, and who had normal occlusion and articulation.

Exclusion criteria were subjects who met the inclusion criteria but were not willing to participate, who had temporomandibular disorders, and patients with disease that caused dysfunction of the masticatory muscles.

The current study was performed with the approval of the Faculty of Dentistry, Universitas Indonesia Ethical Committee, and informed consent was obtained from all subjects, or their guardians, before the experiment.

\section{Questionnaires}

The impact of oral health on the daily life of patients with posterior implant-supported single crowns was calculated as the sum of the scores of all questions in the self-administered questionnaires, OHIP 
49-id, as well as four OHIP questions concerning masticatory ability. One of the most used, complex, and comprehensive indices in the OHIP49 developed by Slade and Spencer, based on Locker's conceptual model of oral health, which is derived from the World Health Organization's classification of the impacts of disease. Built with the purpose to assess the sociopsychological impact of oral pathology, OHIP-49 has been successfully used in clinical studies and has proven good psychometric properties.

The original OHIP- 49 consists of 49 questions, divided after Locker's seven conceptual dimensions of impact (or subscales): Functional limitation, physical pain, psychological discomfort, physical disability, psychological disability, social disability, and handicap. The interviewed patients are asked to indicate how often they experienced a specific impact. Responses for each question are structured on a five-point Likert scale and encoded as following: Never (0), hardly ever (1), occasionally (2), fairly often (3), and very often (4) [13].

Masticatory performance was objectively evaluated by chewing of a piece of color-changeable chewing gum (Fig. 1) (Xylitol, Lotte, Tokyo, Japan) for 60 strokes. The patients were instructed to only chew on their existing implant restoration side. This gum base contains red, yellow, and blue dyes, citric acid and xylitol.

The red dye is $\mathrm{PH}$ sensitive and appears under neutral or alkaline conditions. As the PH inside the chewing gum is kept low by the citric acid, the color of the chewing gum remains yellowish-green before chewing. With the progression of chewing, the color of the chewing gum turns from yellowish-green to red because the yellow and blue dyes seep into saliva, and the red dye appears as a result of elution of the citric acid $[12,14]$. The gum initially had a greenish color and became more-and-more reddish with the duration and intensity of chewing, and there is a strong correlation between color change and masticatory performance and ability.

To assess the color change, the chewed gum extracted immediately after chewing was flattened to a thickness of $1.5 \mathrm{~mm}$ by compressing between two glass plates, and the color position between red and green, positive value indicating redness, and negative value indicating greenness (Figs. 2 and 3) [12,14].

\section{RESULTS}

Some variables have a negative correlation with total OHIP score. The Spearman correlation coefficient between mastication performance and total OHIP score (QoL) was positive if 0.171 but not significant $(\mathrm{p}>0.05)$.

\section{DISCUSSION}

QoL is affected by oral health in the majority of patients. Pre- and postoperative assesments of oral health QoL were significantly different after patients received dental implants. Dental implants therapy has a positive effect on oral health QoL as determined by the OHIP [4]. The observed relationships between masticatory performances of patients with implant-supported single crowns corresponded well with previously reported correlations of occlusal contact on natural teeth [8]. As expected, the values of masticatory performance for patients with posterior implant-supported single crowns were high for color-changeable chewing gum and low for subjective measurement by OHIP 49-id, indicating good mastication performance and QoL.

However, the value of correlation was not significant, and it was assumed because of the limited number of subjects in the current study. The mechanism behind these correlations with implant-supported single crowns may be reflexes elicited from periodontal structures opposing or neighboring natural teeth and receptors in the adjacent periosteum. The hypothesis that osseoperception is caused by remaining parts of the periodontium of the extracted teeth, and that, consequently, early implantation after tooth extraction will lead to better tactile perception than later implantation. Even though an osseointegrated implant is

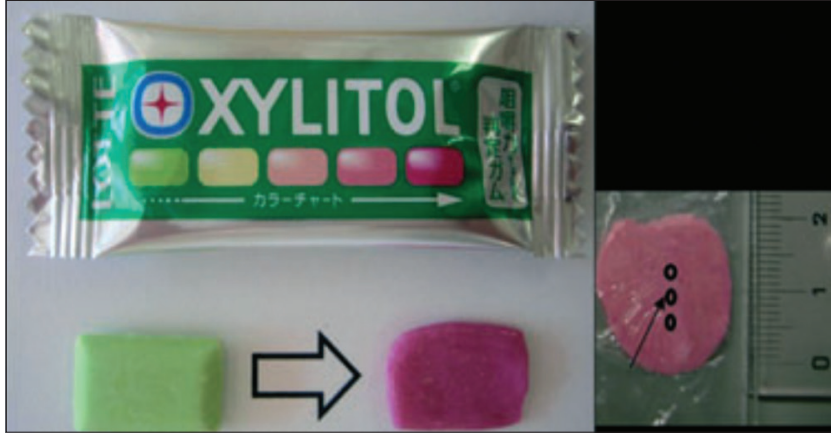

Fig. 1: Color-changeable chewing gum

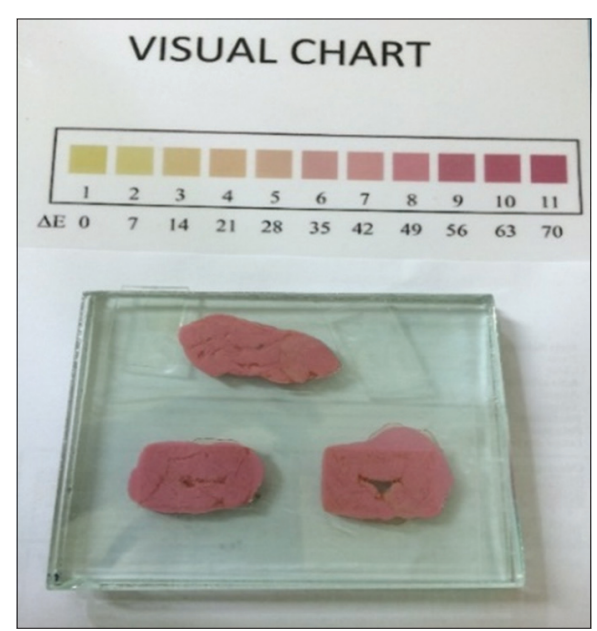

Fig. 2: Gum compressed to a thickness of $1.5 \mathrm{~mm}$

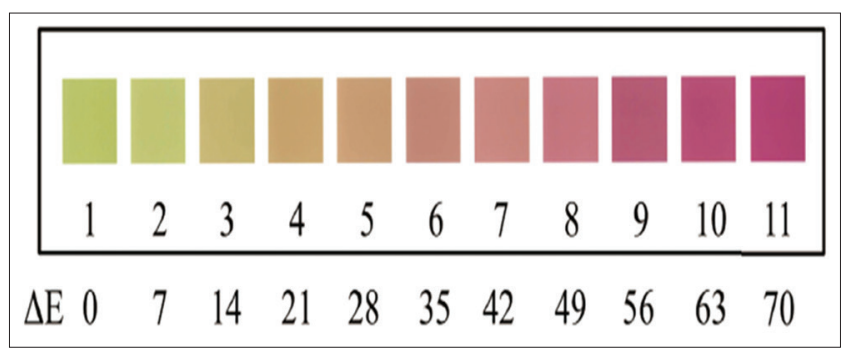

Fig. 3: Visual chart of color-changeable chewing gum

ankylosed by the surrounding bone, it is has a certain physiologic amount of mobility of a natural tooth. This mobility is caused by the elastic deformation of the peri-implant bone when lateral or axial forces are applied on the implant superstructure [15]. To get the results that can be analyzed properly, further investigation is needed.

\section{CONCLUSION}

It can be concluded that there is a correlation between masticatory performance and QoL of patients with posterior implant-supported single crown.

\section{ACKNOWLEDGMENT}

The research leading to these results has received funding from Hibah Publikasi Internasional Terindeks Untuk Tugas Akhir Mahasiswa (PITTA) 2016 from Directorate Research and Community Engagement Universitas Indonesia.

The publication of this manuscript is supported by Universitas Indonesia. 


\section{REFERENCES}

1. Jung RE, Pjetursson BE, Glauser R, Zembic A, Zwahlen M, Lang NP, et al. A systematic review of the 5-year survival and complication rates of implant-supported single crowns. Clin Oral Implants Res 2008; 19:119-30.

2. Pjetursson BE, Lang NP. Prosthetic treatment planning on the basis of scientific evidence. J Oral Rehabil 2008;35 Suppl 1:72-9.

3. Misch EC. Contemporary Implant Dentistry. $3^{\text {rd }}$ ed. Mosby: Elsevier; 2008.

4. Patel N, Vijayanarayanan RP, Pachter D, Choulthard P. Oral Health-Related Quality of Life: Pre-and Post- Dental Implant Treatment. Oral Surg 2014;8:18-22.

5. Brennan DS, Spencer AJ, Roberts-Thomson KF. Tooth loss, chewing ability and quality of life. Qual Life Res 2008;17:227-35.

6. Gotfredsen K, Walls AW. What dentition assures oral function? Clin Oral Implants Res 2007;18 Suppl 3:34-45.

7. Kumar L, Singh BP, Rao J, Singh K. Osseoperceptionin implants supported prosthesis - A review. Online J Med Med Sci Res 2012;1:1-4.

8. Bakke M, Holm B, Jensen BL, Michler L, Möller E. Unilateral, isometric bite force in eight 68-year old woman and men related to occlusal factors. Scand J Dent Res 1990;98:149-58.

9. Bakke M. Mandibular elevator muscles: Physiology, action, and effect of dental occlusion. Scand J Dent Res 1993;101:314-31

10. Endo T, Komatsuzaki A, Kurokawa H, Tanaka S, Kobayashi Y, Kojima K, et al. A two-colored chewing gum test for assessing masticatory performance: A preliminary study. Odontology 2014;102:68-75.

11. Elgestad Stjernfeldt $P$, Wårdh I, Trulsson $M$, Faxén Irving G, Boström AM. Methods for objectively assessing clinical masticatory performance: Protocol for a systematic review. Syst Rev 2017;6:20.

12. Komagamine Y, Kanazawa M, Minakuchi S, Uchida T, Sasaki Y. Association between masticatory performance using a colourchangeable chewing gum and jaw movement. J Oral Rehabil 2011;38:555-63.

13. Grecu AG, Dudea D, Balazsi R, Dumitrascu DL. Romanian version of the oral health impact profile-49 questionnaire: Validation and preliminary assessment of the psychometrical properties. Clujul Med 2015;88:530-6.

14. Ishikawa Y, Watanabe I, Hayakawa I, Minakuchi S, Uchida T. Evaluations of masticatory performance of complete denture wearers using color-changeable chewing gum and other evaluating methods. J Med Dent Sci 2007;54:65-70.

15. Enkling N, Utz KH, Bayer S, Stern RM. Osseoperception: Active tactile sensibility of Osseo integrated dental implants. Int J Oral Maxillofac Implants 2010;25:1159-67. 